\title{
Learner-centered environments: Creating effective strategies based on student attitudes and faculty reflection
}

\begin{abstract}
Catharine F. Bishop ${ }^{1}$, Michael I. Caston ${ }^{2}$, and Cheryl A. King ${ }^{3}$
Abstract: Learner-centered environments effectively implement multiple teaching techniques to enhance students' higher education experience and provide them with greater control over their academic learning. This qualitative study involves an exploration of the eight reasons for learner-centered teaching found in Terry Doyle's 2008 book, Helping Students Learn in a Learner Centered Environment. Doyle's principles were investigated through the use of surveys, student focus group interviews, and faculty discussions to discover a deeper understanding of the effects a "learner-centered" teaching environment has on long term learning in comparison to a "teacher-centered" learning environment. These data revealed five primary themes pertaining to student resistance to learner-centered environments. The results assisted in the development of strategies educators can adopt for creating a successful learner-centered classroom.
\end{abstract}

Keywords: Learner-Centered Teaching, Learner-Centered Environments, Teacher-Centered Environments

\section{Introduction}

Learner-Centered Teaching (LCT) has been an effective approach for enhancing the learning experience for students in higher education (Weimer, 2002). A LCT approach means subjecting multiple teaching actions (method, assignment, or assessment) to the test of a single question: "Given the context of my students, course and classroom, will this teaching action optimize my students' opportunity to learn?" (Doyle, n.d). To be specific, the classroom for a learner-centered environment is quite different from traditional classrooms. Students are required to take on new learning roles and responsibilities beyond taking notes, listening to teachers teach, and passing exams. "It is an environment that allows students to take some real control over their educational experience and encourages them to make important choices about what and how they will learn" (Doyle, 2008, p. xv).

Ferris State University author, educational consultant and professor, Terry Doyle, has assisted higher education faculty in becoming learner-centered teachers through interactive application, regardless of their discipline, in order to enhance the student learning environment. Doyle's extensive experience in faculty development and teaching led to publishing his 2008 book, Helping Students Learn in a Learner Centered Environment, which sets the foundation for this study. The purpose of this study was to gain the student perspective on both effective and ineffective approaches to learning and develop strategies to enhance learning experiences. Through a focus-group inquiry, students were asked about Doyle's (2008) eight reasons students

\footnotetext{
${ }^{1}$ Department of Health Professions, Metropolitan State University of Denver, Campus Box 33, PO Box 173362, Denver, CO 80217-3362, cbisho21@msudenver.edu

${ }^{2}$ Department of Industrial Design, Metropolitan State University of Denver, Campus Box 90, TE124, PO Box 173362, Denver, CO 80217,mcaston3@msudenver.edu

${ }^{3}$ Department of Nursing, Metropolitan State University of Denver, Campus Box 72, P. O. Box, 173362, Denver, CO $80217-$ 3362, cking41@msudenver.edu
} 
resist Learner-Centered Teaching: 1) Old habits die hard; 2) High schools remain teachercentered institutions; 3) Learning is not a top reason students give for attending college; 4) Students don't like taking learning risks; 5) LCT doesn't resemble what students think of as school; 6) Students don't want to give more effort and LCT requires it; 7) Students' mindsets about learning make adapting to LCT more difficult; 8) Many students follow the path of least resistance in their learning. Faculty reflections of student perspectives were coded and analyzed to reveal significant themes. By examining the details of the newly discovered themes, faculty members developed a number of useful strategies to foster a learner-centered environment. For the purposes of this study, Doyle's usage of the term teacher has been chosen to encompass all representations of the term such as instructor, facilitator, adjunct and affiliate faculty, and professor. Below, each of Doyle's eight reasons is summarized.

- Reason One: Old Habits Die Hard

Twelve or more years of teacher-centered instruction contribute to the formation of habits regarding the roles and responsibilities of college students. These habits include sitting quietly in class, doing the homework the teacher assigned, taking notes during class sessions, and answering multiple choice questions on exams. After twelve years, school develops a familiar pattern. Additionally, previous student learning experiences have stressed the importance of memorization over actual learning with understanding. Past learning experiences for the students have focused on the facts and details rather than on the larger themes of cause and consequence of events. The shortfall of these approaches involves memorization of facts with minimal transfer of learning to long-term memory. This discovery reveals that it takes time and practice to develop a new set of learning habits in order to be successful. It is expected that students will occasionally retreat into old patterns, as old habits die hard.

- Reason Two: High Schools Remain Teacher-Centered Institutions

There is substantial research indicating that American high schools are teachercentered and material oriented, not learner-centered. This means teachers are in control of the content and dissemination of material that is subject-based. It is expected that students will sit quietly, take notes, and memorize material for the test. It is fair to assume that college students will be using the same high school learning habits when they enter college because that is what they are used to.

- Reason Three: Learning is Not a Top Reason Students Give for Attending College

Laurence Steinberg, in his ten year study of high school students, reported in his 1996 landmark book, Beyond the Classroom, the most common reason students gave for doing well in school was not interest in the subject, but getting good grades to ensure entry into college. Understandably, many freshman college students have a shocking experience their first semester when they grow weary from being in the same structured academic systems for the past twelve or more years. College is seen as the last mountain to summit in order to obtain a decent paying job. It is a means to an end.

- Reason Four: Students Don't Like Taking Learning Risks

Teachers know that learning entails taking risks and confronting the possibility of failure. Students often see the possibility of failure as a negative experience and something painful that should be avoided. This outlook can inhibit learning. Students then refrain from taking risks and making mistakes to avoid feeling helpless and 
inadequate, which are the very actions that successful thinkers must do in order to protect themselves from being just average. Despite growing up as risk takers in other aspects of their lives, many students fail to maintain a willingness to take risks in a school environment.

- Reason Five: LCT Doesn't Resemble What Students Know as School

By age 18 , it is projected that students have spent approximately $70 \%$ of their lives in school. Students experience school as a place where the teacher does the talking, and the students do the listening, note taking, homework, and take tests that are multiple choice, matching, true and false or essay. The teacher instructs the students on the tasks they are expected to complete and the students do what they are told. The learning choices given to students are usually limited to writing about a topic of choice or choosing a book for which to report. The only area of control students are given over their learning is the degree to which they choose to engage in the learning process, and that control is limited by the consequences that come with choosing not to engage.

It is understandable how our students would be tentative, cautious and rather uncomfortable in a learner-centered environment having never experienced a learning environment where meaningful control and choices about learning were offered or opportunities to participate in first hand learning existed. It is also understandable that students would get upset about a learning approach where the role of the teacher has changed so much that it appears as if they lack focus or interest in his or her job (Doyle, 2008).

- Reason Six: Students Don't Want to Give More Effort

Doyle states, "it is the one who does the work, who does the learning" (Doyle, 2008, p. 25). A common complaint faculty hear from students is that learner-centered teaching requires more work. This study's observation by our students is correct. Students in learner-centered environments will be asked to do more firsthand work, more team and group work, more reflection and more communication with peers. All of these learning activities require a certain amount of effort and are not intended to be passive experiences.

- Reason Seven: Students' Mindsets Towards Learning Make Adapting to LCT More Difficult.

Students with a fixed mindset view intelligence and ability as fundamentally fixed at birth and unchangeable. These students see themselves and others as smart, average, or dumb. Students with fixed mindsets spend a great deal of effort trying to prove their abilities by avoiding failure. This effort to avoid failure actually prevents them from engaging in activities that would ironically make them smarter. This mindset has a profound impact upon students' views of a variety of learning related actions including seeing effort in certain learning activities as being of little or no use. This fixed mindset means tutoring, study buddies, or visits to faculty offices for extra help all appear to be a waste of time to our students. The opposite of a fixed mindset is a Growth Mindset. Students with a growth mindset believe that it is through individual's hard work that true potential is achieved. Students with a growth mindset take learning risks and view failure only as a message that they need to calculate their mistakes and work harder to improve. 
There is general agreement that two types of goals may be set by students. One is a learning goal which is described as the desire to increase one's competency, understanding, and appreciation for what is being learned. The other is a performance goal which involves outperforming others as a means to make others subordinate. Learning goals and performance goals are not mutually exclusive; one can value the task itself and the outcome of the task.

- Reason Eight: Many Students Follow the Path of Least Resistance in their Learning Doyle describes students that take the path of least resistance as "minimalist learners" (2008, p 28). These students often ask questions which include, how many points is this worth? followed by how many points do I need to get an A, B or C grade? These questions reflect a lifetime of learning in environments where gaining a reward or avoiding a punishment was the goal. The goal of minimalist learners is the grade and not the learning. Student motivation for learning has a large impact on the path they choose to take as learners.

\section{Changing to a Learner-Centered Environment}

The following steps provide teachers with the rationale surrounding the process of changing to a learner-centered environment. This information provides useful tools to assist students in developing skills and understanding the importance of becoming life-long learners.

\section{Changes in Our Understandings of How Humans Learn}

Recent neuroscience research has shown that the dendrites of human brain cells only grow when the brain is actively engaged and the neuron-networks formed in the brain only stay connected when they are used repeatedly (Ratey, 2002). Teachers need to continually reinforce to students that the learning tasks required are necessary to optimize the development of the neuron-networks needed to be successful college learners. This is what is required of the students to adapt to the new role of learner. Once this is understood, the student will see that teaching methodologies are part of how the human brain learns and becomes part of long term memory recall. Student participation supports firsthand learning, group learning, practicing, reflecting, teaching of others, and presentations because all of these learning activities require active learner engagement.

\section{Preparing Students for Their Careers}

The rationale for teaching many of the learning skills, behaviors, attitudes, and critical thinking strategies as part of learner-centered college courses is that college students will need these skills for their careers beyond college. When teachers put students into small groups it is not only to promote a deeper level of learning, but also because learning to talk with or listen to others is one of the single most important skills needed to be successful in any career field. Furthermore, another valuable skill for career success is asking students to make class presentations in order to increase their public speaking abilities. Such learning activities contribute to student career goals, yet this may require continual reminders about value and significance of tasks.

3. Preparing Students to be Life-long Learners

The new reality that students must grasp is that their college educational experience is no longer their terminal educational experience. It becomes the teacher's responsibility in colleges and universities to educate students to be life-long learners, 
capable of independent, self-motivated learning as part of their educational experience. When faculty ask students to write copiously, read large amounts of information, learn to manage time, work well with others, accept and give feedback and criticism, express ideas in clear, concise ways that can be easily understood by others, listen attentively, defend a position or idea, or find a proper source, they do so because students will benefit from the development of these life-long skills.

Each time teachers conduct a class activity or give a homework assignment or assessment focusing on a learner-centered environment, student understanding increases regarding the importance of building life-long learning skills. These skills equip students to compete in the global economy of an ever flattening world while maintaining credibility and marketability in the work environment.

4. Preparing Students for today, next semester and tomorrow

Teachers need to help students understand that what they are learning today will be helpful, useful, and necessary to their future learning opportunities. This will then create a powerful reason for them to view all learning more seriously. Emphasizing to students that what is being taught today will be relevant and needed in future courses and in their career will add purpose to their daily experiences.

\section{A. A Learner-Centered Classroom Requires Students to Have New Skills}

One of the basic facts that all teachers/professors know about the learning process is: the one who does the work does the learning. At the same time, being able to successfully do the work in a learner-centered environment will require most students to advance their learning skills. Doyle has identified eight areas where college students will likely need faculty assistance in developing their learning skills:

- Learning how to learn independently

- Developing the communication skills needed to collaborate with others

- Taking more control for their learning

- Teaching others

- Making presentations

- Developing life-long learning skills

- Developing their metacognitive skills - knowing what they know, do not know or misunderstand

- Developing the ability to evaluate themselves, peers, and the teacher

Each of these areas takes a more prominent role in a learner-centered classroom; however, most college students have only limited experiences in these areas. For example, the ability of college students to evaluate the quality of their own work is crucial to their career and life success, but few students have ever been asked to do this. Most college students will need to be taught how to conduct meaningful self-assessment of their work; teachers often do not expect students to know how to do something they have never been taught. The ability to speak well and participate in active listening is another skill set that is often overlooked. These are crucial skills for their professional success. Ironically, these are the very activities that students will demonstrate more often than any other on a day-to-day basis at work. It is important to remember that teachers always check to see what the students already know and can do before making learning assignments. If it is found that students are unskilled or under-skilled, then teachers must teach them these learning skills before expecting them to be successful learners in a learner-centered classroom. 


\section{Methods}

\section{Participants}

This IRB approved study included a focus group interview with 7 students enrolled in undergraduate programs at a large urban university in the Rocky Mountain region of the United States. In addition, 7 university faculty members participated in the reflection process and data analysis based on the focus group interview discourse. Both students and faculty represented a diverse spectrum of disciplines. The method of convenience sampling was used to recruit student-participants within various university disciplines (a) who were currently enrolled at the time of the study, (b) agreed to participate in the interview and survey about student-centered learning, and (c) provided open and honest responses to questions and topics presented. Participating faculty members contacted each of the student-participants via person-to-person or email correspondence.

\section{Data Collection Procedure}

The student-participants took part in a 60 minute focus group interview with pre-determined questions based on input from a 50 question student survey pertaining to Doyle's 8 reasons students resist learner-centered environments. One faculty member facilitated the session and used active interviewing throughout the process. The open-ended questions and active interviewing techniques allowed for further discussion into a participant's response in order to gain deeper meaning (Holstein \& Gubrium, 2003) Sample questions from the focus group interview are shown in Table 1. The faculty-participants documented student responses and provided reflections of the group experience in a 60 minute faculty discussion following the focus group session.

\section{Table 1}

Sample questions from the focus group interview

\section{FOCUS GROUP INTERVIEW QUESTIONS}

- How do you learn best?

- Do you like PowerPoint lectures?

- What kinds of exams do you prefer?

- Do you prefer to learn less and get a good grade or learn more and get a lesser grade?

- What is the role of the professor?

- What is the role of the student?

- What are your thoughts about group work?

- What should be the student's role in classroom decision making?

- Can you describe your best and worst class? 


\section{Data Analysis}

These data were approached from different angles. An initial round of data analysis occurred during the discussion session directly following the focus group interview. In order to increase both credibility and validity, the focus group provided a vehicle for member checking throughout the interview as the facilitator summarized or restated information regarding participant responses. In order to recognize existing patterns on the specific areas specified by Doyle, an inductive analysis of the interview transcripts and documented artifacts (i.e., field notes) was conducted (Johnson \& Christensen, 2004). These data were collected by each faculty member present for the focus group interview. Patterns can be identified from complex data and a greater understanding occurs through the development of emerging themes (Thomas, 2006).

A content analysis of the faculty reflections was conducted from the focus group interview. Both inductive and deductive methods were used to determine core consistencies and meanings of concepts as well as draw new theories from old theories (Zhang \& Wildemuth, 2009). Conclusions from this analysis revealed major themes and/or patterns that were significant to forming strategies to enhance a learner-centered environment.

\section{Results}

Through the analysis of the interviews, surveys, and discussions, a better understanding of a learner-centered environment was achieved. These data were divided into two primary themes: (a) reflections of student responses to Doyle's 8 reasons students resist learner-centered environments; and (b) strategies adopted to create more successful learner-centered environments. Within each theme, sub-themes were identified by recording the most poignant and meaningful statements expressed by each participant in the study. Sub-themes were coded using a color scheme and categorized under one of the primary themes. The following chart indicates each theme and their sub-themes. (Refer to Figure 1)

\section{Primary Theme:}

Reflections of student responses to Doyle's 8 reasons students resist learner-centered environments

- Student Comprehension

- Information Transference

- Assessment Tools

- Student Expectations

- Teacher Expectations

\section{Primary Theme:}

Strategies adopted to create more successful learner-centered environments

- First Day of Class

- Group Work

- Balance

Figure 1. Emerging primary themes and sub-themes from this study. 


\section{Reflections of student responses to Doyle's 8 reasons students resist learner-centered environments}

\section{Student Comprehension}

When students were asked about the best methods for learning in the classroom, they expressed their preference toward visual material, relevance, repetition, teacher enthusiasm, examples, and meaningful lectures. Without a good balance of these desired preferences, students tend to feel disconnected from the subject material.

Student 1: "I definitely learn better visually than memorization.... hands-on."

Student 2: "I feel that both of those [visualization and memorization] go hand-in-hand. I value the texts and lectures and apply that. I've had the most success when my teacher lectures and pulls out what I need."

Student 3: "I learn better in the lecture setting. The more I hear it, the more I write it, the more I learn it. Examples are really good. It celebrates on the whole idea on what they are trying to teach you."

Upon reflection from the observing faculty, it is unanimous that learning practices and comprehension will vary in degree depending on the interests/major of the student. Students that are more experiential in nature tend to gravitate toward career paths that emphasize hands-on application. For instance, Recreation Professions tend to be very experiential in nature; therefore, students will desire a great deal of practical application within the classroom experience (i.e., visual aids, activities, field trip experiences, group projects). Also, it appears that students emphasize the visual aspect of learning more than audio or a combination of both; therefore, visual connection is important between the concept and the desired application. It is also important to convey and discuss the relevance of the learning material to real world experiences and balance lectures with supporting activities.

The views of this focus group towards LCT seem to follow the views represented by students in Doyle's book. In general, the students were comfortable with and had come to expect Teacher-Centered Learning styles that they have experienced from early education through high school and are apprehensive and skeptical of alternative teaching styles. Some faculty expressed great interest when the students discussed the difficulty of college compared to high school; however, when earlier schooling is properly conducted, it should adequately prepare the student for college. Some secondary schools far exceed their duties, expectations, and requirements to prepare its students for college. In college, it is the teacher's responsibility to continue to seek ways to empower and prepare students for careers in specialized fields.

\section{Information Transference}

There are a multitude of tools and techniques used to transfer information from the teacher to the student and between students (i.e., textbook, experiential activities, PowerPoints, overheads, whiteboard/chalkboard lectures, electronic voting systems, etc.). The students overwhelmingly expressed their thoughts about the usage of PowerPoints over all other techniques. Overall, PowerPoints are welcomed only if they are organized and used as a supporting tool to the lecture. The most effective are those that are visual, interactive, and contain less written content. Although textbooks are used to study a particular subject, many students felt that they were too expensive and unnecessary if the teacher reviewed the material in class. Therefore, many students expressed that they would not read or purchase textbooks for their classes and instead 
desired a "hands-on" approach to the material from the teacher either through writing step-bystep procedures or instructions on a whiteboard/chalkboard, relating relevant stories/examples, or through the use of classroom activities.

Student 2: "You are just a robot writing down the notes. That mind-numbing Powerpoint presentation is common."

Student 5: "When a professor is scrambling around, you don't value their knowledge."

Student 6: "PowerPoints can be used as a back-up to the texts."

Student 4: "The book [textbook] is just somebody's thoughts."

After listening to the responses from the students, faculty members concurred that PowerPoints are useful aids for the learning experience. However, black text on a white background can detract the student from the content due to its mundane nature. Students tend to "tune-out" instead of "tune-in" if PowerPoints are dull and do not relate to what is being conveyed by the teacher. A great deal can be done to improve the PowerPoint experience by adding color, animation, video, photos, charts/diagrams, etc. PowerPoints should reflect what the textbook is describing (if a text is used); however, not all valuable and current information will be in the textbook, so it is necessary to supplement. In fact, there are many ways that teachers can keep the students actively engaged. For example, the teacher can give the students the PowerPoints before a class, leaving blanks within the text of each slide. Students would need to attend class and be attentive in order to fill in the missing information (represented with a blank space). This is just one example that helps to increase attendance and classroom engagement.

\section{Assessment Tools}

When asked about the techniques used to assess what the students have learned, varied responses manifested. In particular, a great deal of the discussion surrounded the use of exams as a tool to measure learning. When asked, the students wanted to express that the actual learning was the most important goal; however, in reality, their focus was on getting a good grade more than anything. They were focused on the importance of quiz/test/exam for the end result of the grade rather than the learning experience. The focus group also discussed their high levels of anxiety regarding the teacher's methods of assessment. Many had different preferred styles of testing (i.e., multiple choice questions, true or false, essay); and a handful would often "cram" before exams.

Student 6: "Multiple Choice? They reword it so it's all tricky."

Student 1: "Depends on the job [discipline]. Practical exams are good to an extent. For example: Math exams."

Student 4: "The pressure forces me to learn and that could be beneficial [pop quizzes]."

Student 6: "I cram every weekend. An hour or two. I can't wait until the end [exam day]. I would fail."

Student 4: "It's easier to cram for a True and False or Multiple Choice rather than a short answer. Multiple Choice is a short term memory. Even though I don't like them [essay], I learn more."

Student 4: "I think grades are important to the overall outcome."

Student 3: "During the process, it's not all that fun. It's the sacrifice. But I do enjoy learning. I may not enjoy the process, but I enjoy learning."

The faculty members in this study agreed that there is a lot of value in using exams if the questions are structured well, and simple traditional methods such as these are easier for the teacher to grade. This may explain why teachers use multiple choice and true/false more often 
than other assessment testing styles. However, if a teacher intends to develop the critical thinker within, then an essay exam may be the best option. Faculty members also questioned the effectiveness of "cramming" and felt that students cannot digest the information fully by "cramming". Long-term retention is not successfully reached when students "cram" for an exam; therefore, altering assessment methods may be necessary in order to enhance true learning (Doyle, 2008). Again, practical experience and "hands-on" projects may be the best avenue to learning in regards to certain interest areas and majors because students are actively engaged with the content. The question that each teacher might want to contemplate concerning their course material is whether students can learn just as much through the execution of a traditional classroom delivery or by means of practical application? This continues to be a subject for constant debate. However, it may all depend on a student's particular area of study whether practical experiences are more beneficial.

\section{Student Expectations}

The role of the student in the classroom was a key theme that varied in attitudes and beliefs among the focus group panel members. Overall, the focus group students expressed that while it is the professor's duty to convey the information, it is the students' role to understand the material and apply it, ultimately to learn the course information. Furthermore, some students felt that it was their own responsibility to seek out additional help from the professor if they needed it. However, it is also interesting to note that some students also expressed that their performance in the class often depended on how much they respected the professor; in other words, they feel compelled to put forth more effort in the class if the professor shows concern for their learning. This view is more reflective of Teacher-Centered Learning, putting the onus back on the teacher for the extent of learning the student accomplishes.

Student 7: "[Our responsibility is] being able to understand the material and applying it."

Student 4: "If you have a teacher that you respect, you feel like you are letting them down."

Student 3: "It is important for the student to be mindful."

Student 1: "I got A's where I haven't done anything in class!"

Faculty responded openly and honestly to this theme stressing that a teacher cannot make a student learn, but she/he can help a student understand the importance of learning. A teacher takes on many roles as a teacher and it is important to determine effective and efficient teaching philosophies that also reflect the mission of the institution for which they are employed.

\section{Teacher Expectations}

The students in this study felt that a teacher's role is to provide the necessary information and knowledge to allow the student to adequately complete the course. They desired to have someone to act as a mentor and to whom they could relate to. Often times, this occurs in small classes rather than a large lecture class. Having an "open-mind" and the capacity to successfully demonstrate different learning styles in a professional and respectful manner were key characteristics expressed by this focus group. Most importantly, they desired the teacher to provide a clear path to an often overwhelming "sea" of information. In other words, simplify the material.

Student 6: "It is the student's responsibility to make the relationship."

Student 3: "I feel better in class when I'm respected as a student, and it is a professor that I can go to." 
Student 2: "Important that they [professors] weed through the stuff and give you a path to follow."

Student 1: "I can tell if the professor is just doing the day-to-day and those that are teaching with more passion."

Student 3: "It depends on their [professor's] personality and learning style. Some will do well with that and some won't."

Upon reflection, the faculty felt that the students wanted a teacher that showed a passion for what they are teaching; students will often emulate the energy of the teacher. It was important to acknowledge that teachers should want their students to be excited about learning. It is the obligation of the teachers to be enthusiastic about what is being taught. In addition, it is also essential to attempt to make a connection with the student as an individual or at least make a classroom connection; a connection that exudes respect, trust, and honesty.

Faculty also got the impression from the students in the focus group that a professor's primary role is to control the structure of the class so that expectations of student behavior and performance are clearly outlined and that the content of the course material is delivered in a straightforward and traditional manner. Deviations from this "norm" (that is, LCT styles) such as group work, allowing students to have a say in the structure of the course, allowing "free" discussion in the classroom, etc., are viewed as unprofessional shortcomings of the professor as if the professor was "copping out" or not doing his/her job. The challenge, as Doyle pointed out, is in the transition from "Teacher-Centered" to "Learner-Centered" Teaching styles and explaining to students why LCT is important. In other words, a teacher needs to be a chameleon in that he/she must adjust to the needs of each individual classroom. Each group of students will bring a different set of unique energies and dynamic; therefore, it is important that the teacher can adjust accordingly. If a classroom needs more structure and direction (i.e., Freshman students), then use a teaching style that best fits those needs.

\section{Strategies adopted to create more successful learner-centered environments (See Table 2)}

Table 2

Strategies to create successful learner-centered environments

\begin{tabular}{|c|c|}
\hline STRATEGY & CONCEPTS \\
\hline First Day of Class & $\begin{array}{l}\text { - Create a classroom dynamic that helps students to get to know one another } \\
\text { - Explain teacher's role and qualifications } \\
\text { - Explain course expectations as well as teacher's expectations } \\
\text { - Give students some control over the learning experience by negotiating the } \\
\text { - Consider incorporating games, group initiatives or other challenging activities }\end{array}$ \\
\hline Group Work & $\begin{array}{l}\text { - Have a discussion on the benefits of group work with students } \\
\text { - } \quad \text { Demonstrate how group work is reflective of the future work environment } \\
\text { - } \quad \text { Have group appoint a group leader } \\
\text { - } \quad \text { Have group leader appoint tasks based on members' skill levels and strengths } \\
\text { - } \quad \text { Use peer evaluations as part of the assessment of group projects }\end{array}$ \\
\hline Balance & $\begin{array}{l}\text { - } \quad \text { Vary the presentation styles for new course content } \\
\text { - } \text { Link new course content to the course objectives and discuss relationship to } \\
\text { - Include repetition of course information to increase memory retention } \\
\text { - } \quad \text { Emphasize information through frequent review } \\
\text { - } \quad \text { Provide varying types of assessments to determine true learning }\end{array}$ \\
\hline
\end{tabular}




\section{Discussion}

A discussion and summarization of the thematically categorized findings provide an explanation of their importance, meaning, and significance. Ultimately, three strategic subthemes emerged that set the foundation for planning and implementing a successful learner-centered environment: (a) first day of class; (b) group work; and (c) balance. Proactive measures are proposed and recommendations discussed in order to establish best practices.

\section{First Day of Class}

The first day of class can often be an awkward experience for both the student and the teacher; however, there are many effective strategies for creating a learner-centered environment and establishing a sense of comfort. Attempting to make a meaningful connection with students may require the willingness to be vulnerable during introductions. It is important to share personal and academic philosophies, outline qualifications for teaching the course, and explain the importance and relevance of the course. In return, try to ask the students about their motivations for taking the course and provide a platform to openly discuss expectations. Examples of some questions could include: (a) As a teacher, what do you expect from me?; (b) As a student, what should I expect from you?; and (c) As a student, what do you expect to get out of the class? Understandably, many students may be reluctant to share or express their ideas and thoughts on the first day of class and instead, these questions could be revisited after a couple of weeks have passed.

Many students want to know the most significant information that will help them to succeed. In a learner-centered environment, this does not include reading the course syllabus without allowing the opportunity for students to review, discuss, and negotiate this contract. Of course, there are policies and regulations set by the institution that are nonnegotiable; however, many syllabus items can be discussed openly. The most popular items that promote inclusion into a student-learning environment are: (a) assignment timelines; (b) possibilities for field trips/site visitation experiences; (c) inviting guest speakers; (d) consequences for tardiness/absences; (e) project deadlines; and (f) extensions on projects. These items can be discussed and a collective agreement can be achieved between the teacher and the students. This gives the students a voice regarding their academic experiences and sets an agreement that is better tailored to their individual uniqueness.

Implementing an open student-centered environment produces many classroom benefits. It can create an atmosphere of comfort, invite open expression, invite meaningful class discussions, allow for the development of peer learning, and nurture student-teacher and studentstudent connections. A teacher can initiate group activities, interactive challenges, name games, dyads, and friendly competition to assist with achieving a successful student-centered environment. The process takes time and will often extend beyond the first day, yet it can be accomplished with teacher commitment and student participation.

\section{Group Work}

Group work is an essential component of a student's learning experience. The adage, "two heads are better than one" is typically true here, but may not appear so to students on the surface. Students interviewed in our focus group expressed dislike for group work and preferred to work individually. Despite student objections, there are a lot of benefits to small group learning. The 
challenge then for the teacher is to communicate these benefits to the students so that they are "on board" with group work. At the beginning of a group project, take some time to lead a discussion of the pros and cons and let the students evaluate how the pros outweigh the cons.

Working within a group is reflective of the working world environment where employees are usually required to collaborate with others and communicate on a daily basis. Businesses are looking for employees who have a strong ability to communicate and contribute to teams (McDougall \& Beattie, 1995). Demonstrate the value in group work by relating it to real world situations where group work helped bring success to a project or a business. Students will be more "on board" when they can see the big picture.

When working in groups, students have an opportunity to share concepts and ideas and learn from one another (peer tutoring). This increase in learning opportunities helps a student integrate a larger available amount of information than if they were working alone (Serva \& Fuller, 1997). Additionally, groups are able to take on bigger tasks than possible alone; "the sum of the whole vs. the sum of the parts. Each student has their own unique set of strengths, thus, when working together, the group can benefit from the skills and experiences of each individual.

Design your group work to align with the course learning objectives and be consistent within a real world framework in order to help students see the big picture value behind the project. At the beginning of the project, every group member must see the end result of the work as something achievable and important beyond just getting a good grade in the class. Before setting students out on group tasks, equip them with group management skills - conflict resolution, project management, and communication (both tools and skills). Complete small exercises that help students explore these concepts and practice various solutions with no penalty to their grade. Assess the students' individual strengths and weaknesses and suggest that the group appoint a group leader who can then assign tasks according to members' skill levels and strengths. Students will learn more if they divide the workload and deal with nuances of group dynamics on their own. Step in to mediate only when the group cannot resolve issues internally.

One of the biggest objections that students have towards group work is the fear of having a social loafer in their group. Social loafers are group members who do not carry their own weight or participate to the level expected of them as individual members of the group. Social loafing tends to increase with big projects, large group sizes, and lack of peer evaluation (Aggarwal \& O'Brien, 2008). It is recommended that large, semester-long projects be broken up into multiple parts which help to make the work requirements and deadlines feel more immediate. Decreasing your group size also helps reduce the possibility of social loafing. Very large groups allow individuals to "hide" while small groups reduce anonymity and increase the pressure for individuals to participate and contribute. Furthermore, allow your students to evaluate each member in the group. It is recommended to do this not only at the end of the project, but also at a mid-point in the project. Through peer-monitoring, an identified social loafer has an opportunity to become a stronger contributor to the group before the conclusion of the project (Felder \& Brent, 2001).

\section{Balancing}

Teachers and students each have their own individual preferences as to the method they prefer to deliver or receive course information (e.g. PowerPoint lectures, textbook reading assignments, hands-on activities, or group projects). Through our focus group, we discussed various presentation methods with the students and received mixed responses. Some students felt they learned best with a structured PowerPoint lecture where the teacher is following a prescribed 
format, while others preferred to be given a choice in how they learn course material (e.g. through hands-on activities, discussions and group activities and peer interactions, videos, or reading the textbook on their own time - outside of the classroom).

We concluded that the best LCT approach an educator can have when presenting new material in order to facilitate learning is to address a variety of presentation methods in their instruction plan. PowerPoint slides with images, hands-on exercises, and group discussions all present different opportunities to utilize various senses and thus create and strengthen neural connections in the brain in different ways. By varying our delivery, we help keep the student engaged with the content and retain the course content for the long term (Doyle, 2011).

Whichever presentation method selected, it is important to relate all new course material and assignments to the course objectives. Furthermore, relate information in the course to other courses in the program that the student has taken or will be taking so students will understand "why" it is important to learn this material. It is important for students to see that the material they are learning in their courses is connected to a set of skills and knowledge that will prepare them for success in their professional career and a lifetime of learning (Doyle, 2008). When students are aware of the value of the material they are learning, they will learn more and retain more.

Repetition helps students retain the course information in long-term memory which will help them recall it at later dates and apply it to new situations and make new connections (Mohs, 2010). The more often information is repeated and used, the more likely this will occur. When presenting new material, repeat it in several ways. Sometimes this is inherent in our presentation of material. For example, when giving a PowerPoint presentation, material is repeated through the use of many senses. Students hear the material verbally presented. They also see the information up on the screen. They write it down in their notebooks, and they read it back to themselves at a later time. Field trips are also a good example of repetition in learning. When students can see the concepts covered in class in action out in the field, it becomes a reality in their minds. A teacher could also require students to conduct outside research for one or more projects during the semester. Explain the importance of getting outside the classroom and interacting with local professionals to derive a deeper understanding of the course material. For example, in the field of Industrial Design, good design does not come from within oneself, but rather it comes from talking to and observing others, building on existing concepts, then developing new ideas, trying, failing, and trying again.

Revisiting and reviewing information after a period of time has passed is also an effective way to help students retain the material in long-term memory (Ratey, 2002). Effective ways to do this also include discussions, summary writing, and journaling. Not only is repetition helpful with memorizing information, but it can also be a means of emphasizing and reinforcing especially important course material. Ways to emphasize information include telling a story, giving a demonstration, going on a field trip, or bringing in a guest speaker to help reinforce that information.

As discussed earlier, relating the classroom activities to the course material and objectives at all times is critical for students see the importance of the material in the long term beyond just getting a good grade on the exam or getting a passing grade in the class. It is not uncommon for students to assume that what they are learning is only valuable if it is being graded. So, how we assess our students' work can affect how or how much they learn.

There are many types of assessments we can give our students to judge whether or not they learned the material in a course (i.e., writing assignments, exams with multiple choice/short 
answer/essay, projects and presentations, and so forth.) These evaluation types differ in the way students are expected to prove their understanding of the material presented during the semester. Since students are engaged in learning through different ways, providing flexibility in assessment options for our students can allow testing to be more than just an opportunity for the students to regurgitate the information that we fed them all semester; it is an opportunity for them to use their learning strengths or individual talents to demonstrate what they've learned and how that might be applied to new areas beyond the classroom, beyond college, and into their professional careers to make a real difference in the world.

\section{Conclusion}

In general, the students were comfortable with and had come to expect Teacher-Centered Learning styles experienced from early education and high school and were apprehensive and skeptical of alternative teaching styles. It then becomes the responsibility of the teacher to continue to seek ways to empower and prepare students for careers in specialized fields. Various tools, techniques, and strategies assist in this learning process. For instance, PowerPoints are welcomed, but only when organized and used as a supporting tool to the lecture. The most effective are those that are visual, interactive, and contain less written content. Students from the focus group discovered that they were fixated on the importance of the quiz/test/exam for the end result of the grade rather than the learning experience. The faculty members in this study agreed that there is value in using exams when the questions are structured well. Furthermore, the focus group students expressed that while it is the professor's duty to convey the information, it is the students' role to understand the material and apply it, and ultimately to learn the course information. Students desired that a teacher provide a clear path to an often overwhelming "sea" of information. In other words, simplify the material for them. Faculty also got the impression from the students in the focus group that a professor's primary role is to control the structure of the class so that expectations of student behavior and performance are clearly outlined and that the content of the course material is delivered in a straightforward and traditional manner.

The challenge, as Doyle pointed out, is in the transition from "Teacher-Centered" to "Learner-Centered" Teaching styles and explaining to students the importance of LCT. Implementing an open student-centered environment produces many classroom benefits. It can create an atmosphere of comfort, invite open expression, invite meaningful class discussions, allow for the development of peer learning, and nurture student-teacher and student-student connections. The student learning experience can also benefit by the essential component of group work. Many times, working within a group is reflective of the working world environment where employees are often required to collaborate with others and communicate on a daily basis. For example, students may practice roles and expectations that one might experience as a committee member in any professional organization. Based on the focus group results, we conclude that the best approach a teacher can have in presenting new material in order to facilitate learning is to address a variety of presentation methods in their instruction plan such as visual presentations, memorization exercises, discussion, lectures, and experiential applications. When understood, students welcome the opportunity to influence their learning and gain greater control over their experiences through interactive classroom discussion and negotiation. It is important to understand that as teachers, we are here to coach and to help instill the love of learning in students so that they may become life-long learners and positively impact our world. 


\section{Acknowledgments}

Contributions to the research reported in this study were made by the 2012-2013 Faculty Learning Community at Metropolitan State University of Denver: Nancy K. Sayre, Jeffrey R. Helton, Jeff Hammond, Mark Potter, Lin Huang, and Douglas Mpondi. Equal distribution of research and authorship occurred for this article.

\section{References}

Aggarwal, P., \& O’Brien, C. (2008). Social loafing on group projects: Structural antecedents and effect on student satisfaction. Journal of Marketing Education, 30(3), 255-264. doi: $10.1177 / 0273475308322283$

Bjork, R.A. (1994). Memory and metamemory considerations in the training of human beings. In J. Metcalfe and A. Shimamura (Eds.), Metacognition: Knowing About Knowing, (pp. 185-205). Cambridge, MA: MIT Press.

Doyle, T. (n.d.) The definition of Learner Centered Teaching [Web log post]. Retrieved from http://learnercenteredteaching.wordpress.com/learner-centered-teaching-resources/definition-oflearner-centered-teaching/

Doyle, T. (2008). Helping students learn in a learner-centered environment: A guide to facilitating learning in higher education. Sterling, VA: Stylus Publishing.

Doyle, T. (2008, October). Thriving in academe - A clear rationale for learner-centered teaching. Advocate. Retrieved from http://learnercenteredteaching.wordpress.com/articles-andbooks/the-learner-centered-classroom/

Doyle, T. (2011). Learner-centered teaching: Putting the research on learning into practice. Sterling, VA: Stylus Publishing.

Dweck, C. (2000). Self Theories: Their roles in motivation, personality and development. Philadelphia, PA: Psychology Press.

Felder, R.M., \& Brent, R. (2001). Effective strategies for cooperative learning. J. Cooperation \& Collaboration in College Teaching, 10(2), 69-75.

Felder, R.M. \& Brent, R. (2005). Understanding student differences. Journal of engineering education, 95(1), 57-72.

Goldberg, E. (2001). The executive brain frontal lobes and the civilized mind. New York, NY: Oxford University Press.

Grace, H.A. (March 1955). A teacher-centered theory for education. Peabody Journal of Education, 32(5), 273-281. doi: 10.1080/01619565509536582

Holstein, J. A., \& Gubrium, J. F. (2003). Active interviewing. In J. Gubrium \& J. Holstein 
(Eds.), Postmodern interviewing, (pp. 67-80). Thousand Oaks, CA: Sage Publications. doi: $10.4135 / 9781412985437 . n 4$

Horton, W. (2010). E-learning by design. San Francisco, CA: Pfeiffer.

Johnson, B., \& Christensen, L. (2004). Educational research: Quantitative, qualitative, and mixed approaches. Boston: Pearson Education.

Lom, B. (2012). Classroom activities: Simple strategies to incorporate student-centered activities within undergraduate science lectures. The Journal of Undergraduate Neuroscience Education, 11(1), A64-A71.

McDougall, M. \& Beattie, R.S. (1995). Learning from learning groups. Journal of Management Development, 14(8), 35-41. doi: 10.1108/02621719510097406

Mohs, R. C. (2010). How human memory works. Retrieved from http://heatlh.howstuffworks.com/human-body/systems/nervous-system/human-memory4.htm

National Research Council, Committee on Developments in the Science of Learning, National Research Council, \& Committee on Learning Research and Educational Practice. (2000). How people learn: Brain, mind, experience, and school (Expanded Ed.). Washington, D.C.: National Academy Press.

Ratey, J. (2002). A user's guide to the brain. New York, NY: Pantheon Books.

Serva, M., \& Fuller, M. (1997). Proceedings from the 1997 ACM SIGCPR conference on computer personnel research: Computers and People Research. New York: ACM.

Simon, H. A. (1996). Observations on the sciences of science learning. Paper prepared for the Committee on Developments in the Science of Learning for the Sciences of Science Learning: An Interdisciplinary Discussion. Department of Psychology, Carnegie Mellon University.

Smith, G.A. (2008, September). First-day questions for the learner-centered classroom. The National Teaching and Learning Forum. Retrieved from http://www.ntlf.com/issues/v17n5/v17n5.pdf

Steinberg, L. (1997). Beyond the classroom. Why school reform has failed and what parents need to do. NewYork: Simon and Schuster.

Sylwester, R. (1995). A celebration of neurons: An educator's guide to the human brain. Alexandria, VA: ASCD Publication.

Tagg J. (2003). The Learning Paradigm College. Bolton, MA: Anker.

Thomas, D.R. (2006). A general inductive approach for qualitative data analysis. American Journal of Evaluation, 27(2), 237-246. doi: 10.1177/1098214005283748 
Weimer, M. (2002). Learner centered teaching. San Francisco, CA: Jossey Bass.

Weimer, M. (2008, December 4). Three factors that affect social loafing. Faculty Focus. Retrieved from http://www.facultyfocus.com/articles/teaching-and-learning/3-factors-that-affectsocial-loafing/

Weimer, M. (2012, February 22). My students don't like group work. Faculty Focus. Retrieved from http://www.facultyfocus.com/articles/teaching-professor-blog/my-students-dontlike-group-work/

Weimer, M. (2012, August 1). Does powerpoint help or hinder learning? Faculty Focus.

Retrieved from http://www.facultyfocus.com/articles/teaching-professor-blog/does-powerpointhelp-or-hinder-learning/

Zhang, Y., \& Wildemuth, B. M. (2009). Qualitative analysis of content. In B. Wildemuth (Ed.), Applications of social research methods to questions in information and library science. (pp.308319). Westport, CT: Libraries Unlimited.

Zull, J. (2002). The Art of Changing the Brain. Sterling, VA: Stylus. 